\title{
Antioxidant Responses in Harvested Leaves of Two Cultivars of Spinach Differing in Senescence Rates
}

\author{
D. Mark Hodges ${ }^{1}$ and Charles F. Forney \\ Atlantic Food and Horticulture Research Centre, Agriculture and Agri-Food Canada, 32 Main Street, \\ Kentville, Nova Scotia, B4N 1J5, Canada \\ Wendy V. Wismer ${ }^{2}$ \\ School of Nutrition and Food Sciences, Acadia University, Wolfville, Nova Scotia, BOP 1X0, Canada
}

AdDitional INDEX wORDs. cultivar evaluation, hydrogen peroxide, lipid peroxidation, oxidative stress, postharvest, Spinacia oleracea, storage quality

\begin{abstract}
Aвstract. The objective of this study was to assess responses of certain antioxidants in harvested leaves of selected cultivars of spinach (Spinacia oleracea L.) differing in postharvest senescence rates in order to explore the significance of these antioxidants in postharvest senescence regulation and dynamics. Ten cultivars were grown in both field plots and laboratory growth chambers, harvested at maturity, and their leaves detached and stored at $10{ }^{\circ} \mathrm{C}$ in the dark. Following postharvest analysis, two cultivars were identified consistently as having relatively high ('Spokane F1') and low ('BJ 412 Sponsor') postharvest senescence rates. These two cultivars were then grown in a growth chamber for 45 days and their leaves detached and stored as above. At the point of harvest (day 0 ) and on days 4, 8, 12, 16, and 20, samples were analyzed for activities of ascorbate peroxidase (ASPX; EC 1.11.1.11), catalase (CAT; EC 1.11.1.6), and superoxide dismutase (SOD; EC 1.15.1.1), and (ii) concentrations of malondialdehyde (MDA, an indicator of lipid peroxidation), total ascorbate, reduced ascorbate (AsA), oxidized ascorbate (DAsA), total glutathione, reduced glutathione (GSH), and oxidized glutathione (GSSG). Although MDA accumulated in leaves of both cultivars concomitant with time after detachment, levels became significantly higher in 'Spokane F1'. It is argued that declining activities of ASPX and levels of ascorbate and increasing activities of SOD manifested in accumulation of hydrogen peroxide in 'Spokane F1', leading to a greater potential for lipid peroxidation in this cultivar than for 'BJ 412 Sponsor'. SOD activities and glutathione levels may have increased as a result of elevated oxidative stress in 'Spokane F1'. Increased hydrogen peroxide accumulation in 'Spokane F1' relative to 'BJ 412 Sponsor' may have contributed to an increased rate of senescence in the harvested leaves of this cultivar.
\end{abstract}

Senescence refers to the genetically regulated process leading to death of cells, organs, or whole organisms, and is often accompanied in plants by morphological changes and/or alterations in biochemical and biophysical properties of cellular metabolism. Leaf senescence in particular may involve degradation of proteins, chlorophyll (Hodges and Forney, 2000), nucleic acids (Buchanan-Wollaston, 1997), and/or membranes (Trippi and Thimann, 1983). Physical detachment of leaves has been demonstrated to promote or accelerate symptoms of early leaf senescence (Bartoli et al., 1996; Philosoph-Hadas et al., 1991).

Although active oxygen species such as superoxide $\left(\mathrm{O}_{2}^{-}\right)$and hydrogen peroxide $\left(\mathrm{H}_{2} \mathrm{O}_{2}\right)$ are normal by-products of cellular metabolism, if their production exceeds their scavenging potential (i.e., oxidative stress) they may play important roles in peroxidation of essential phospholipids and in both nucleic acid and protein denaturation (Hodges, 2001). Increased proliferation of active oxygen species (AOS) within plant systems is apparently a common denominator of many types of stresses (Foyer et al., 1994). AOS have also been implicated in induced or natural

Received for publication 24 July 2000. Accepted for publication 15 May 2001. Atlantic Food and Horticulture Research Centre contribution 2213. The authors wish to thank Kerry Barrett and Mark Johnston for technical contributions and Wilhelmina Kalt and Robert Prange, Atlantic Food and Horticulture Research Centre, Kentville, Nova Sotia, for critical review of this manuscript. Partial funding of this project was made possible by grants from Melvin Farms Ltd. and the Matching Investment Initiative program of Agriculture and Agri-Food Canada to D.M.H and C.F.F, and from the Natural Sciences and Engineering Research Council to W.V.W. The cost of publishing this paper was defrayed in part by the payment of page charges. Under postal regulations, this paper therefore must be hereby marked advertisement solely to indicate this fact.

${ }^{1}$ Corresponding author; e-mail: HodgesM@em.agr.ca.

${ }^{2}$ Current Address: Faculty of Agriculture, Forestry and Home Economics, University of Alberta, Edmonton, Alberta, T6G 2P5, Canada. senescent processes and its dynamics (Droillard et al., 1987; Hodges and Forney, 2000; Philosoph-Hadas et al., 1994).

Plants contain complements of enzymic and nonenzymic antioxidants which play a role in regulating levels of AOS such as $\mathrm{O}_{2}^{-}, \mathrm{H}_{2} \mathrm{O}_{2}$, the hydroxyl radical $(\bullet \mathrm{OH})$, and singlet oxygen $\left({ }^{1} \mathrm{O}_{2}\right)$. These antioxidants include the enzymes ascorbate peroxidase (ASPX; EC 1.11.1.11), catalase (CAT; EC 1.11.1.6), and superoxide dismutase (SOD; EC 1.15.1.1), water soluble compounds such as ascorbate, gluathione, and phenolic components, and lipid-soluble compounds such as the carotenoids and tocopherols. SOD dismutates $\mathrm{O}_{2}^{-}$to $\mathrm{H}_{2} \mathrm{O}_{2}$, which is further reduced to $\mathrm{H}_{2} \mathrm{O}$ by CAT in the peroxisomes and by peroxidases such as ASPX in the cytosol and chloroplasts through concomitant oxidation of ascorbate. Both ascorbate and glutathione can also react directly with and scavenge certain AOS (Foyer et al., 1994; Hodges, 2001).

As involvement of AOS in leaf senescence has been well established, it is not surprising that relations between leaf oxidative and antioxidative potentials have been implicated in the dynamics of senescence (Hodges and Forney 2000; Kunert and Ederer, 1985). Philosoph-Hadas et al. (1994) and Meir et al. (1995) provide evidence that general leaf reductant levels are negatively correlated with the rate of senescence for a number of herbaceous species. Hodges and Forney (2000) demonstrated that levels of ASPX, CAT, and ascorbate play influential roles in the dynamics and severity of senescence in detached spinach (Spinacia oleracea L.) leaves, suggesting that regulation of $\mathrm{H}_{2} \mathrm{O}_{2}$ is an important factor in the process of senescence. Although $\mathrm{H}_{2} \mathrm{O}_{2}$ itself is not particularly toxic, and can act as a signal molecule in plant responses to both abiotic and biotic stresses (Foyer et al., 1997), it can react with $\mathrm{O}_{2}^{-}$in the metal-catalyzed Haber-Weiss reaction to form the very potent oxidizer $\bullet \mathrm{OH}$ 
(Salin, 1988). Thus detoxification of $\mathrm{H}_{2} \mathrm{O}_{2}$ is extremely important in regulating levels of other AOS within plant systems (Hodges, 2001; Hodges et al., 1997a, 1997b).

Many studies have attempted to correlate antioxidant capacities with tolerance to stresses such as chilling temperatures (Schöner and Krause, 1990), exposure to ozone (Ranieri et al., 1996), ultraviolet irradiance (Rao et al., 1996), salt (Olmos et al., 1994), and drought (Li et al., 1998). Although many of these investigations examined antioxidant capacities of sensitive and tolerant plants in relation to stress responses, only a few of these studies (e.g., Gossett et al., 1994; Hakam and Simon, 1996; Hodges et al., 1996) compared antioxidant levels between sensitive and tolerant plants of the same species. The objective of the present study was to assess responses of certain antioxidants in detached leaves of two cultivars of spinach differing in senescence rates in order to explore the significance of these antioxidants in senescence regulation and dynamics.

\section{Materials and Methods}

Plant material. The storage potential of 10 cultivars of spinach was initially evaluated from tissue produced under both field and laboratory conditions. The 10 cultivars examined were: Unipack 12 , Unipack 151, Samish, BJ 412 Sponsor, BJ Spectrum F1, BJ Spindrift F1, Space F1, Rushmore, St. Helens, and Spokane F1. Seeds of 'Samish', 'Rushmore' and 'St. Helens' were obtained from Chriseed (Mount Vernon, Wash.) while 'Space F1', 'Spectrum F1', 'Spindrift F1', 'Spokane F1' and 'BJ 412 Sponsor' were obtained from Bejo (Warmenhuizen, Holland, The Netherlands). 'Unipack 12' and 'Unipack 151' were obtained from Peto Seeds (Saticoy, Calif.)

Fieldevaluation. Three replicates of 25 seeds per cultivar were field sown (TUO84>OSW84; friable fine sandy glaciofuvial sediment) in Canning (lat. $45^{\circ} 10^{\prime} \mathrm{N}$, long. 6463'W), Nova Scotia, on 4 June 1998 and again at the same location on 15 July 1998. Seeds were hand-planted at a depth of $2.5 \mathrm{~cm}$ in rows $3 \mathrm{~m}$ long and $30 \mathrm{~cm}$ apart in a randomized complete block design. This first planting was harvested on 22 July 1998 and the second on 1 September 1998. On each harvest date all tissue except for the bottom four leaves was removed from the plants. The leaves were then submerged in a 1.5 ${ }^{\circ} \mathrm{C}$ water bath for $6 \mathrm{~min}$, followed immediately by removal of excess water. Tissue was either analyzed immediately (day 0) or stored as described below.

LABORATORY EVALUATION. The spinach cultivars (60 seeds/ cultivar) were sown $1.5 \mathrm{~cm}$ deep in potting soil (3 peatmoss : 2 perlite : 2 sand), three seeds per $60-\mathrm{cm}^{3}$ standard pot. Pots were placed in a growth chamber(Econaire GR36; Econaire, Winnipeg, Manitoba, Canada) maintained at $18{ }^{\circ} \mathrm{C}$ and $95 \%$ relative humidity $(\mathrm{RH})$ with a photocycle of 10:14 L:D. The lamps (cool-white fluorescent) provided a photosynthetic photon flux density of 400 to 450 $\mu \mathrm{mol} \cdot \mathrm{m}^{-2} \cdot \mathrm{s}^{-1} 15 \mathrm{~cm}$ above soil level (LI-188B quantum sensor; LICOR, Lincoln, Nebr.) Plants were routinely watered and fertilized twice weekly with water-soluble $15 \mathrm{~N}-15 \mathrm{P}_{2} \mathrm{O}_{5}-18 \mathrm{~K}_{2} \mathrm{O}$ (Plant Products, Brampton, Ontario, Canada) as per directions. Spinach was grown for $45 \mathrm{~d}$ and then all leaves except for the four oldest were harvested. As with the field experiment, the leaves were submerged in a $1.5^{\circ} \mathrm{C}$ water bath for $6 \mathrm{~min}$, followed immediately by removal of excess water. Tissue was either analyzed immediately (day 0 ) or stored as described below. This experiment was conducted twice.

Storage Conditions. The $300 \mathrm{~g}$ fresh weight (FW) samples of harvested spinach leaves were placed in perforated plastic bags. Bags were then sealed and placed in a chamber (Econaire GR 100) maintained without light at $10^{\circ} \mathrm{C}$ and with a $\mathrm{RH} \geq 95 \%$. Samples to be analyzed for cultivar evaluation were removed from storage on days $0,5,8,12$, and 15 . Fresh tissue was used immediately for all malondialdehyde (MDA) and electrolyte leakage assays whereas samples were frozen and stored $\left(-40^{\circ} \mathrm{C}\right)$ for later analyses of chlorophyll.

LABORATORY GROWTH. After identifying cultivars 'BJ412 Sponsor' and 'Spokane F1' as exhibiting good and poor storage potential, respectively, based on MDA, chlorophyll, and electrolyte leakage profiles, both cultivars were grown, harvested, and stored under controlled laboratory conditions for antioxidant evaluation as described above with the exception that tissue was removed from storage on days $0,4,8,12,16$, and 20 . Fresh tissue was used immediately for all MDA and antioxidant enzyme assays whereas frozen samples were stored for later analyses of antioxidant compounds.

LIPID PEROXIDATION AND CHLOROPHYLL ANALYSES. Estimates of lipid peroxidation were assessed spectrophotometrically in 7.5 to 10 $\mathrm{gFW}$ samples of spinach tissue using a modified thiobarbituric acidmalondialdehyde (TBA-MDA) assay (Hodges et al., 1999) which corrects for compounds other than the TBA-MDAs adduct which absorb at $532 \mathrm{~nm}$. Chlorophyll was determined in 7.5 to $10 \mathrm{~g} \mathrm{FW}$ samples of spinach leaves as described by Wintermans and De Mots (1965).

ELECTROLYTE LEAKAGE. Electrolyte leakage was estimated from electrical conductivity using a modified method of Kuo and Parkin (1989). Three replicates of eight leaf discs $2 \mathrm{~cm}$ in diameter were removed from each cultivar and placed into $50 \mathrm{~mL}$ test tubes containing $35 \mathrm{~mL}$ of $0.4 \mathrm{~m}$ mannitol in deionized water. The samples were equilibrated for $1 \mathrm{~h}$ in a $24^{\circ} \mathrm{C}$ circulating water bath. Initial electrical conductivity following the $1 \mathrm{~h}$ incubation was read using a conductivity meter (DsPH-3; Presto-Tek, Los Angeles, Calif.). Samples were then frozen for $24 \mathrm{~h}$ and electrical conductivity read to provide a $100 \%$ electrical conductivity reading. Electrolyte leakage was calculated as a percentage of total electrical conductivity recorded after $1 \mathrm{~h}$.

Antioxidant ENZyMe anAlyses. Enzyme extracts were prepared by homogenizing spinach leaves ( 7.5 to $10 \mathrm{~g} \mathrm{FW}$ ) in a prechilled mortar and pestle nestled in ice along with $0.5 \mathrm{~g}$ inert sand, 0.5 g polyvinylpolypyrrolidone, and $30 \mathrm{~mL}$ chilled extraction buffer consisting of $100 \mathrm{~mm}$ potassium phosphate buffer ( $\mathrm{pH} 7.5), 1.0 \mathrm{~mm}$ EDTA, and 1.0 mm ascorbate added just before use. The extraction buffer used for the SOD assays lacked ascorbate. Extracts were then centrifuged (Sorvall RC-5C plus; Dupont Instruments) at 10,000 $g_{n}$ for $15 \mathrm{~min}$ at $2^{\circ} \mathrm{C}$ and the supernatants analyzed. For SOD assays, the supernatants were immediately depleted of low-molecularweight compounds by passage through a minicolumn (Sephadex G25 PD-10; Pharmacia Biotech, Uppsala, Sweden) preequilibrated with the extraction buffer. Enzyme assays were conducted immediately following extraction.

All enzymes were assessed spectrophotometrically at $25^{\circ} \mathrm{C}$ on an Ultraspec 3000 (Pharmacia Biotech) equipped with an Endocal RTE-5B (Neslab, Portsmouth, N.H.) water bath for calibrated temperature control.

ASPX was determined using a method described by Nakano and Asada (1987). The assay mixture contained $90 \mathrm{~mm}$ potassium phosphate buffer ( $\mathrm{pH} 7.0$ ), $0.1 \mathrm{~mm}$ EDTA, $0.65 \mathrm{~mm}$ ascorbate, and $1.0 \mathrm{mM} \mathrm{H} \mathrm{H}_{2} \mathrm{O}_{2}$. The reaction was initiated with the addition of approximately $40 \mu \mathrm{g}$ extract protein. Activity was determined by following the $\mathrm{H}_{2} \mathrm{O}_{2}$-dependent decomposition of ascorbate at 290 nm.

CAT activity was assayed in a reaction mixture containing 100 mм potassium phosphate buffer ( $\mathrm{pH}$ 6.5), $1.0 \mathrm{~mm}$ EDTA, $60.0 \mathrm{~mm}$ 
$\mathrm{H}_{2} \mathrm{O}_{2}$, and $\approx 40 \mu \mathrm{g}$ extract protein following a protocol of Aebi (1983). Activity was determined by following the decomposition of $\mathrm{H}_{2} \mathrm{O}_{2}$ at $240 \mathrm{~nm}$.

SOD activity was determined according to McCord and Fridovich (1969) as modified by Hodges et al. (1997a). The reaction mixture consisted of $65.0 \mathrm{~mm}$ potassium phosphate $(\mathrm{pH} 7.5), 0.01 \mathrm{~mm}$ EDTA, 0.5 mм xanthine, 0.13 mм cyctochrome $c$, and 0.025 units xanthine oxidase (units as defined by Sigma Chem., St. Louis, Mo.). Activity was determined by monitoring inhibition of the reduction rate of cyctochrome $c$ between reaction mixtures with and without protein extract (up to $200 \mu \mathrm{g}$ protein) at $500 \mathrm{~nm}$.

Protein concentration was determined spectrophotometrically at $595 \mathrm{~nm}$ using the Bio-Rad Protein Assay Dye Reagent Concentrate (Bio-Rad Laboratories, Hercules, Calif.; catalogue no. 500-0006) using a method based on Bradford (1976). Bovine gamma-globulin $\left(0.25\right.$ to $\left.1.4 \mathrm{mg} \cdot \mathrm{mL}^{-1}\right)$ was used as a standard reference.

ANTIOXIDANT COMPOUND ANALYSES. Reduced ascorbate (AsA), oxidized ascorbate (DAsA), and total ascorbate (AsA + DAsA) were determined spectrophotometrically according to Law et al. (1983) as modified by Hodges et al. (1996). Over ice, 7.5 to $10 \mathrm{~g} \mathrm{FW}$ of spinach tissue was homogenized with $0.5 \mathrm{~g}$ inert sand and $15 \mathrm{~mL}$ of ice-cold freshly prepared $5 \%(\mathrm{w} / \mathrm{v}) m$-phosphoric acid with a mortar and pestle. The homogenate was centrifuged at $10,000 g_{\mathrm{n}}$ for $15 \mathrm{~min}$ at $2^{\circ} \mathrm{C}$. Total ascorbate was determined by incubating at 25 ${ }^{\circ} \mathrm{C}$ for $50 \mathrm{~min}$ in a $700 \mu \mathrm{L}$ total volume $100 \mu \mathrm{L}$ supernatant, $110 \mathrm{~mm}$ $\mathrm{KH}_{2} \mathrm{PO}_{4}, 3.6 \mathrm{~mm}$ EDTA, and $1.5 \mathrm{~mm}$ dithiothreitol (DTT) to reduce all DAsA to AsA. After incubation, $100 \mu \mathrm{L}$ of $0.5 \%(w / v) ~ N-$ ethylmaleimide (NEM) was added to remove excess DTT. AsA was treated in a similar manner except that $200 \mu \mathrm{L}$ deionized $\mathrm{H}_{2} \mathrm{O}$ was substituted for DTT and NEM. Color was developed in both series of reaction mixtures (total and reduced ascorbate) with the addition of $400 \mathrm{~L} 10 \%$ (w/v) TCA, $400 \mu \mathrm{L} 44 \% o$-phosphoric acid, $400 \mu \mathrm{L}$ of $65 \mathrm{~mm} \alpha-\alpha^{1}$-dipyridyl in $70 \%$ ethanol, and $200 \mu \mathrm{L} 110 \mathrm{~mm} \mathrm{FeCl}_{3}$. The reaction mixtures were then incubated at $40{ }^{\circ} \mathrm{C}$ for $1 \mathrm{~h}$ in a shaking water bath (Julabo Labortechnik, Seelbach, Germany) and quantified at $525 \mathrm{~nm}$. AsA and DAsA standards were between 0 and $5 \mathrm{~mm}$ in $5 \%(\mathrm{w} / \mathrm{v}) m$-phosphoric acid. For each sample, DAsA was estimated from the difference between total ascorbate and AsA.

Total glutathione, reduced glutathione (GSH), and oxidized glutathione (GSSG) were determined spectrophotometrically following Griffith (1980) as modified by Hodges et al. (1996). Over ice, 7.5 to $10 \mathrm{~g} \mathrm{FW}$ spinach tissue was homogenized in a mortar and pestle along with $0.5 \mathrm{~g}$ inert sand and $15 \mathrm{~mL}$ of ice-cold freshly made $5 \%(\mathrm{w} / \mathrm{v}) 5$-sulfosalicylic acid. The homogenate was centrifuged at $10,000 g_{\mathrm{n}}$ at $2{ }^{\circ} \mathrm{C}$ for $15 \mathrm{~min}$. Two solutions were then prepared. Solution A ( $\mathrm{pH} 7.2$ ) consisted of $100 \mathrm{~mm} \mathrm{Na} \mathrm{HPO}_{4} \cdot 7 \mathrm{H}_{2} \mathrm{O}, 40 \mathrm{~mm}$ $\mathrm{NaH}_{2} \mathrm{PO}_{4} \cdot \mathrm{H}_{2} \mathrm{O}, 15 \mathrm{mmEDTA}, 1.8 \mathrm{~mm}$ 5,5'-dithiobis-(2-nitrobenzoic acid), and $0.04 \%(\mathrm{w} / \mathrm{v})$ BSA. Solution B (pH 7.2) consisted of 1.0 $\mathrm{mm}$ EDTA, $50 \mathrm{~mm}$ imidazole, $0.2 \%$ (w/v) BSA, and 2 unit $/ \mathrm{mL}$ glutathione reductase (units as defined by Sigma Chem.). Total glutathione was measured in a reaction mixture consisting of $400 \mu \mathrm{L}$ solution $\mathrm{A}, 320 \mu \mathrm{L}$ of solution $\mathrm{B}, 400 \mu \mathrm{L}$ of a $1: 25$ dilution of supernatant in $0.5 \mathrm{M} \mathrm{KH}_{2} \mathrm{PO}_{4}(\mathrm{pH} 7.0)$, and $80 \mu \mathrm{L}$ of $3.0 \mathrm{~mm}$ $\mathrm{NAPDH}$. The reaction rate was measured by following the change in absorbance at $412 \mathrm{~nm}$ for $5 \mathrm{~min}$. GSSG was analyzed in a similar manner except that $1.0 \mathrm{~mL}$ of $1: 10$ diluted supernatant in $0.5 \mathrm{M}$ $\mathrm{KH}_{2} \mathrm{PO}_{4}$ (pH 6.5) was first incubated with $20 \mu \mathrm{L}$ 2-vinylpyridine at $25^{\circ} \mathrm{C}$ for $1 \mathrm{~h}$ to derivatize GSH. GSH and GSSG standards were between 0 and $18 \mu \mathrm{M}$ in $5 \%$ (w/v) 5-sulfosalicylic acid diluted

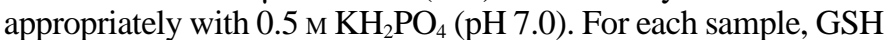
was estimated from the difference between total glutathione and GSSG.
Statistical analyses. All antioxidant enzyme, antioxidant compound, TBA-MDA, and chlorophyll results were based on at least three readings each of three samples from all harvests. Electrolyte leakage experiment results were from one reading each of three samples per harvest Harvests were conducted twice for the cultivar selection (10 cultivars) and metabolite analyses (two cultivars) experiments. Effects of cultivar, harvest, and storage were analyzed using a completely randomized design. Data were subjected to analysis of variance procedures and least significant difference (LSD) values were calculated using Genstat (release 4.1) software (Genstat 5 Committee, 1997). Unless otherwise noted, only results significantly different at $P \leq 0.05$ are discussed.

\section{Results}

Cultivar Selection. Results of the field and growth chamber selection trials are shown in Figs. 1-3. Harvested leaves of only two cultivars, 'BJ 412 Sponsor' and 'Spokane F1', hereafter referred to as Sponsor and Spokane, respectively, exhibited consistent relatively slow and fast senescence rates, respectively, based on the indicators MDA level, chlorophyll loss, and electrolyte leakage. Data from the other eight cultivars are not presented.

Lipid peroxidation levels, as assessed by MDA, increased in both Sponsor and Spokane after $8 \mathrm{~d}$, although Spokane demonstrated a more rapid increase in the field after day 15 and on day 12 in the laboratory trials (Fig. 1). However, there were no differences in MDA levels between field-grown Sponsor and Spokane until $15 \mathrm{~d}$ after detachment, at which point Spokane exhibited more peroxidation. Similarly, no differences in MDA levels between lab-

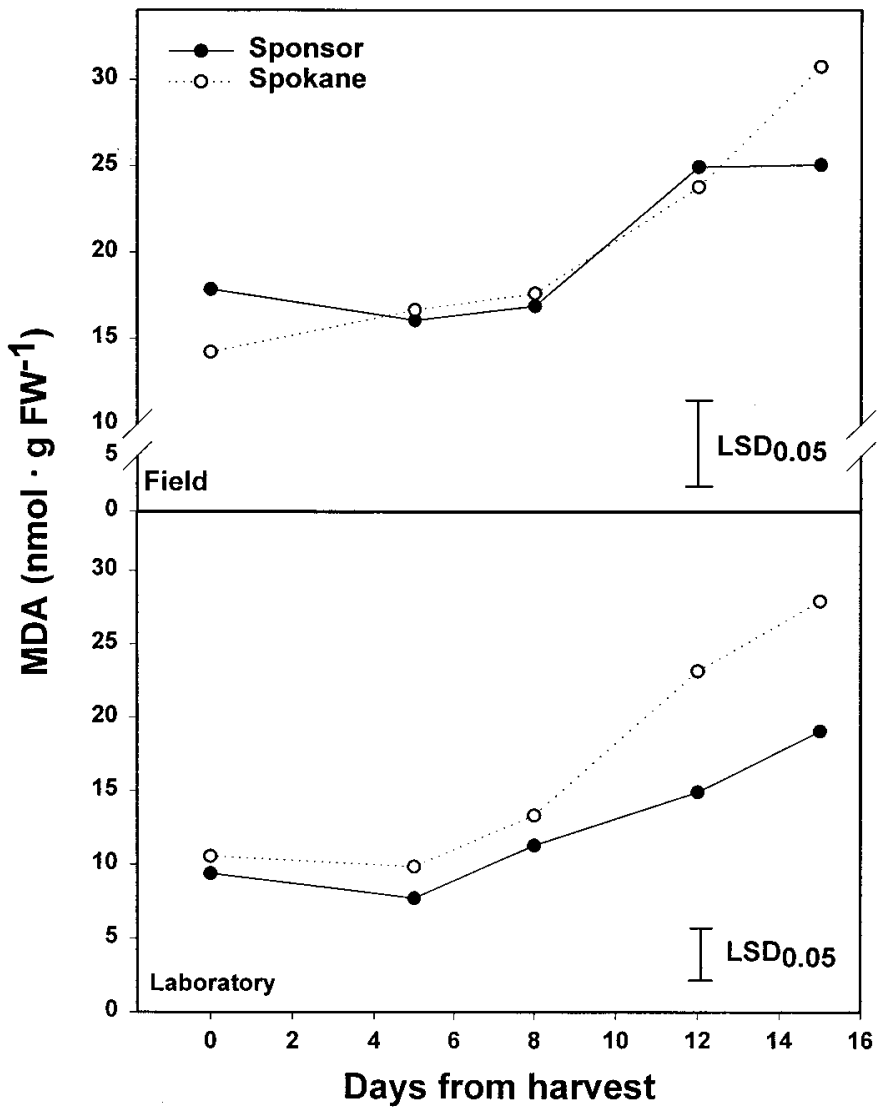

Fig. 1. Changes in MDA over time in detached leaves of Sponsor and Spokane stored at $10^{\circ} \mathrm{C}$ in the dark with $\mathrm{RH} \geq 95 \%$. Plants were grown initially in the field or in a growth chamber. Symbols represent means and of six independent replicate samples from two harvests. 


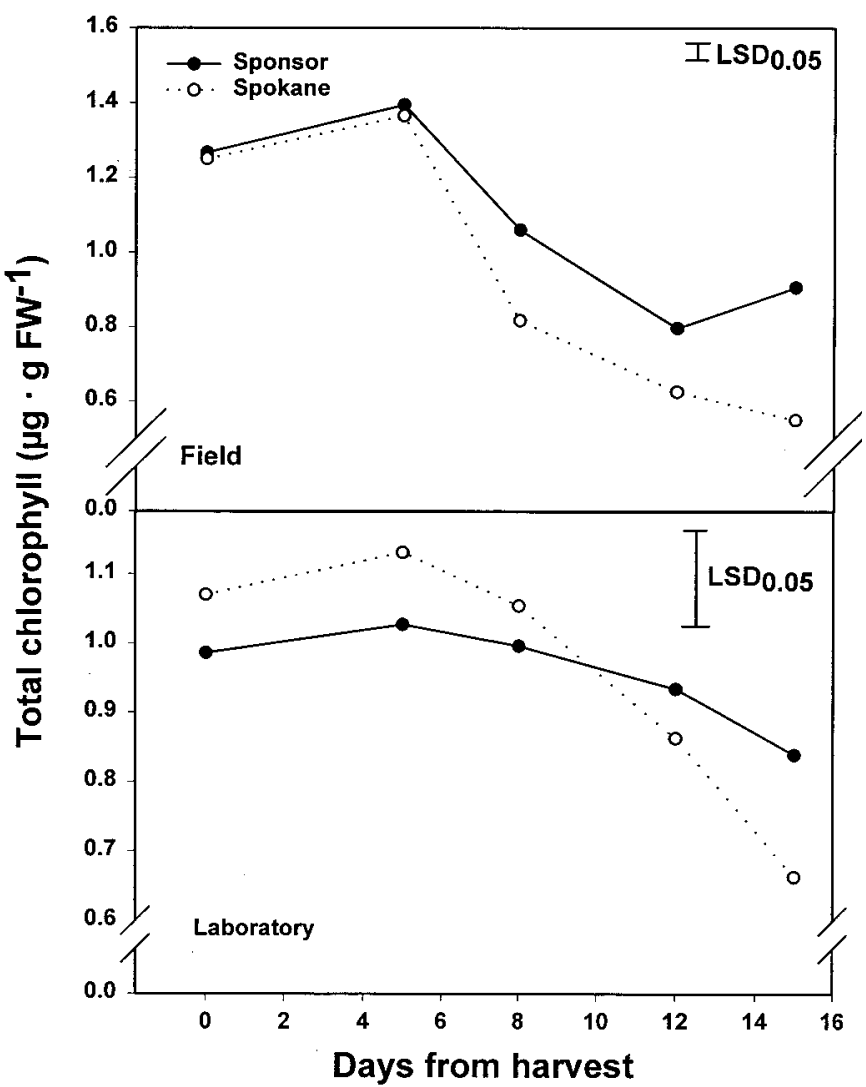

Fig. 2. Changes in total chlorophyll over time in detached leaves of Sponsor and Spokane stored at $10^{\circ} \mathrm{C}$ in the dark with $\mathrm{RH} \geq 95 \%$. Plants were grown initially in the field or in a growth chamber. Symbols represent means and of six independent replicate samples from two harvests.

grown Sponsor and Spokane were noted before day 12, after which Spokane displayed higher levels.

Both field and laboratory grown leaves of Sponsor and Spokane exhibited a loss in total chlorophyll levels over time (Fig. 2). This loss was more rapid in Spokane than in Sponsor.

Electrolyte leakage, as measured by conductance, increased after day 12 in both field- and laboratory-grown cultivars (Fig. 3). Electrolyte leakage of Spokane was not different from Sponsor following the $15 \mathrm{~d}$ postdetachment period for leaves produced in the growth chamber, although it increased marginally in leaves of Spokane relative to Sponsor after day 12 in the field-grown cultivars.

ANTIOXIDANT AND MDa ANALYSES. As with the growth chamber cultivar selection test, MDA levels in detached leaves of both Sponsor and Spokane increased $8 \mathrm{~d}$ following detachment (data not presented). No differences in MDA levels between lab-grown Sponsor and Spokane were noted before day 16, after which Spokane displayed higher levels than Sponsor.

Although there were no differences in ASPX activities between Sponsor and Spokane leaves over the entire 20-d postdetachment period, ASPX activity of Spokane declined significantly after day 8 compared with initial levels, whereas ASPX activity of Sponsor remained essentially unchanged following detachment (Fig. 4A). There were no noted differences in activities of CAT between Sponsor and Spokane leaves over the 20-d postdetachment period, nor did they change from day 0 values for either cultivar (Fig. 4B). However, a trend of increasing CAT activity with storage was apparent. Leaves of Spokane exhibited a steady increase in SOD activity which became significant after $12 \mathrm{~d}$ and then remained relatively constant during the remainder of the storage period (Fig. 4C). In contrast, SOD activity in Sponsor increased for $8 \mathrm{~d}$ and then began to decline on day 12 . These divergent patterns of change resulted in SOD activity of Spokane being significantly higher than that of Sponsor on day 20.

Total leaf ascorbate declined $8 \mathrm{~d}$ and $12 \mathrm{~d}$ following detachment in Sponsor and Spokane, respectively (Fig. 5A). The slightly higher level of total ascorbate in detached Spokane as compared to Sponsor noted at the time of harvest was maintained throughout the storage period. Similarly, oxidized:reduced ascorbate (DAsA:AsA) values only decreased following detachment in Sponsor leaves, though no differences were noted in these ratios between Sponsor and Spokane following detachment (Fig. 5B).

There was no change in total glutathione between Sponsor or Spokane following leaf detachment (Fig. 5C). Although total glutathione in Sponsor remained unchanged during storage, it increased after day 8 for Spokane. Reduced:oxidized glutathione (GSH:GSSG) ratios of Spokane leaves increased after day 16, and more dramatically so for Spokane after day 12 (Fig. 5D). Leaf GSH:GSSG levels were higher in Spokane than Sponsor leaves on day 20.

\section{Discussion}

Levels of MDA, a secondary end product of polyunsaturated fatty acid oxidation, are indicative of the degree of plant oxidative stress (Hodges et al., 1999), while decreases in chlorophyll concentration as thylakoid proteolipids are mobilized and the rate of

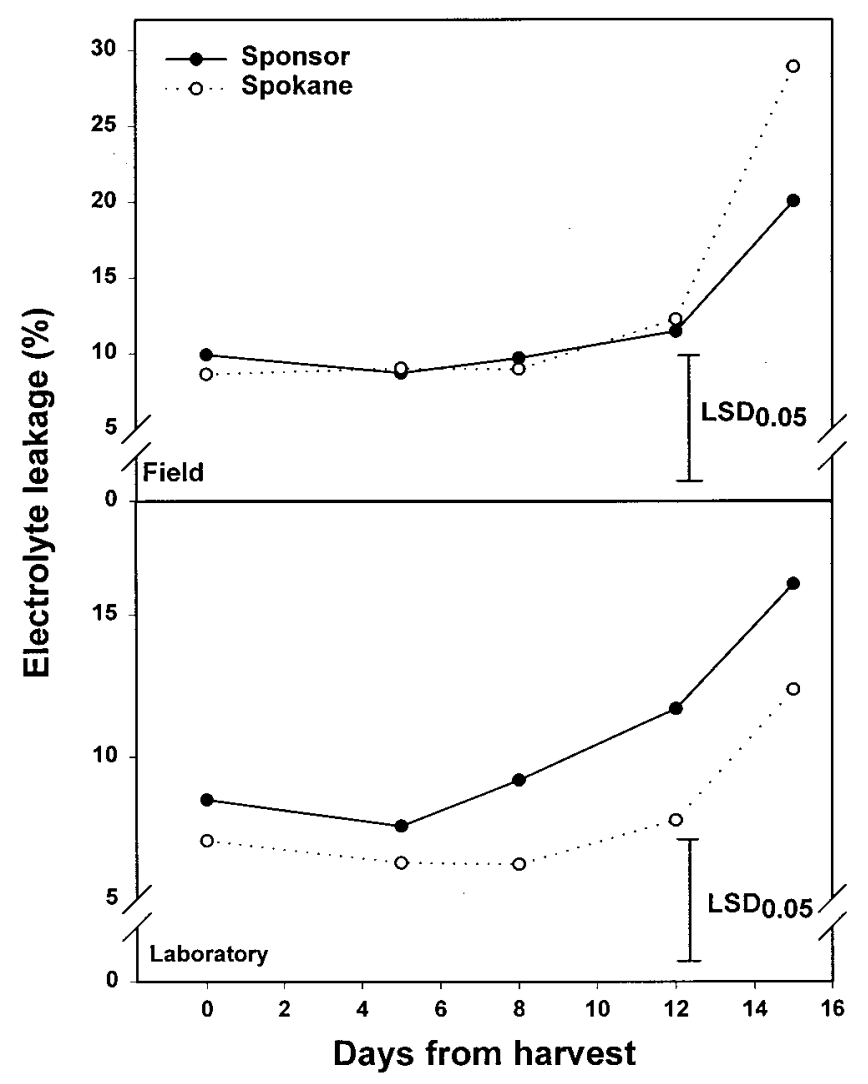

Fig. 3. Changes in electrolyte leakage over time in detached leaves of Sponsor and Spokane stored at $10^{\circ} \mathrm{C}$ in the dark with $\mathrm{RH} \geq 95 \%$. Plants were grown initially in the field or in a growth chamber. Symbols represent means and of six independent replicate samples from two harvests. 
photosynthesis declines often serve to gauge the extent of induced or natural senescence (Hodges and Forney, 2000; Meir et al., 1995). Electrolyte leakage, while providing an estimate of the scale of membrane permeability (Lyons et al., 1979; Wismer et al., 1998), also provides an indication of senescence-related loss of lipid/ membrane integrity.

Recording changes in MDA and chlorophyll contents and electrolyte leakage during postharvest storage of spinach leaves of the 10 cultivars allowed for identification and selection of two cultivars which differed in their senescence rates. Although Sponsor and Spokane began to experience senescence 8 to $12 \mathrm{~d}$ after detachment, as evidenced by significant increases in MDA levels and electrolyte leakage, Spokane F1 exhibited a higher rate of senescence than Sponsor both in the field and in laboratory growth chambers. Moreover, postdetachment chlorophyll loss occurred more rapidly in Spokane leaves as compared to those of Sponsor.

AOS have been implicated in induced or natural senescent processes (Hodges and Forney, 2000; Thompson et al., 1991). Reduced membrane integrity, as indicated by increased electrolyte leakage, is a common phenomenon in plant senescence (Thompson, 1984). Subsequent effects of disruptions in membrane integrity on

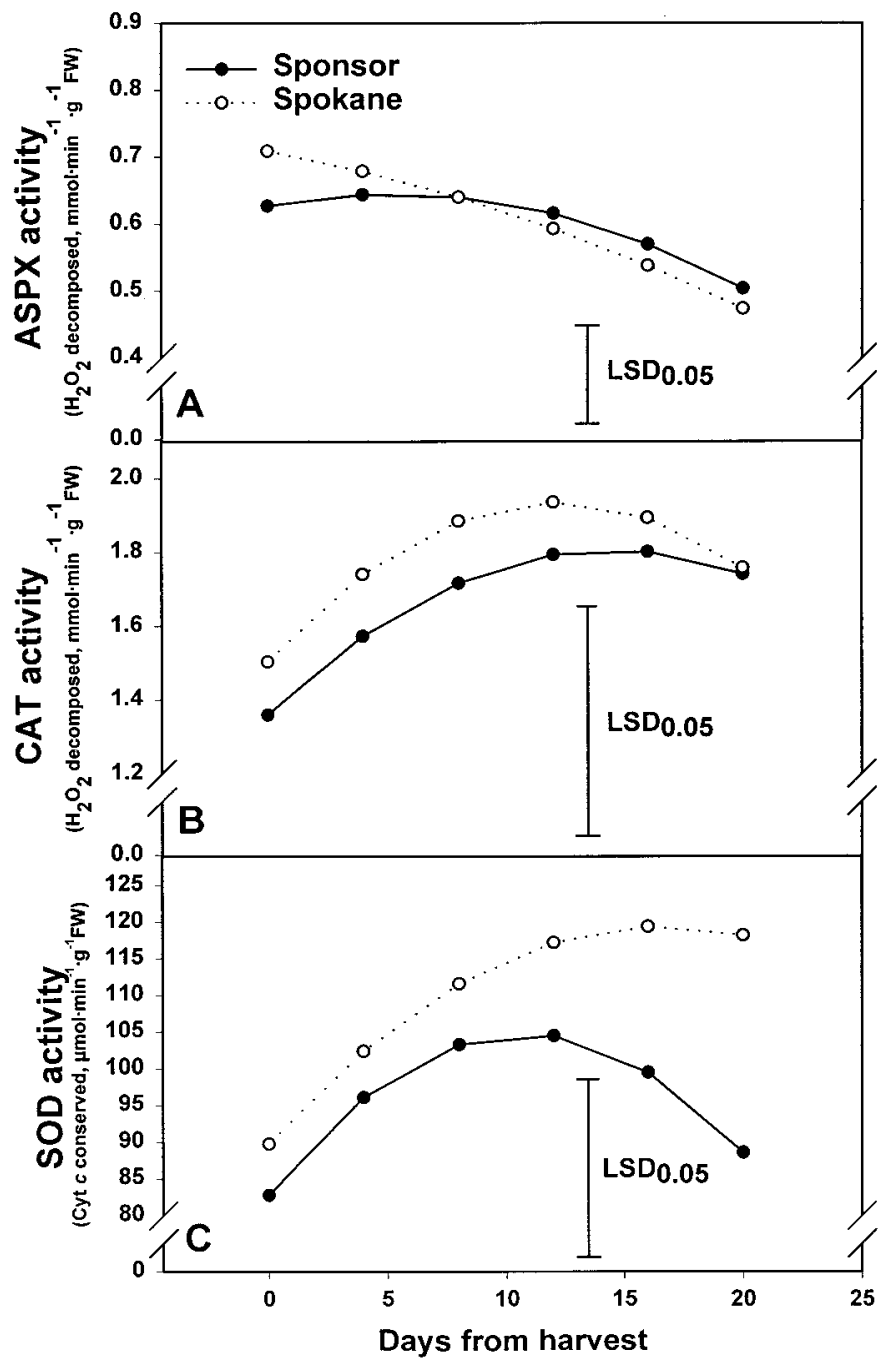

Fig. 4. Changes in (A) ASPX, (B) CAT, and (C) SOD activities over time in detached leaves of Sponsor and Spokane spinach stored at $10^{\circ} \mathrm{C}$ in the dark with $\mathrm{RH} \geq 95 \%$. Plants were grown initially in a growth chamber. Symbols represent means of six independent replicate samples from two harvests. organellar stability can lead to enhanced production of AOS through unregulated electron transport reactions. Moreover, AOS can cause deesterification of lipids, resulting in increased levels of polyunsaturated fatty acids. These polyunsaturated fatty acids can become peroxidized directly by AOS in chain-style reactions or can act as the substrate of lipoxygenase to form hydroperoxy conjugated dienes (Hildebrand, 1989). Not only are AOS such as ${ }^{1} \mathrm{O}_{2}$ and $\mathrm{O}_{2}^{-}$released as by-products of lipoxygenase activity (Chamulitrat et al., 1991; Kanofsky and Axelrod, 1986), but fatty acid hydroperoxides can also directly promote AOS accumulation; for example, they can react with $\mathrm{Fe}^{+2}$ to form $\bullet \mathrm{OH}$. Peroxidized polyunsaturated fatty acids can also act as ionophores, admitting extracellular $\mathrm{Ca}^{+2}$, which in turn may induce/enhance activities of calmodulin-mediated lipases (Thompson et al., 1991), which function to de-esterify phospholipids, producing more substrate for lipoxygenases. A cycle of membrane degradation, loss of membrane integrity, AOS generation, and exacerbated senescence results.

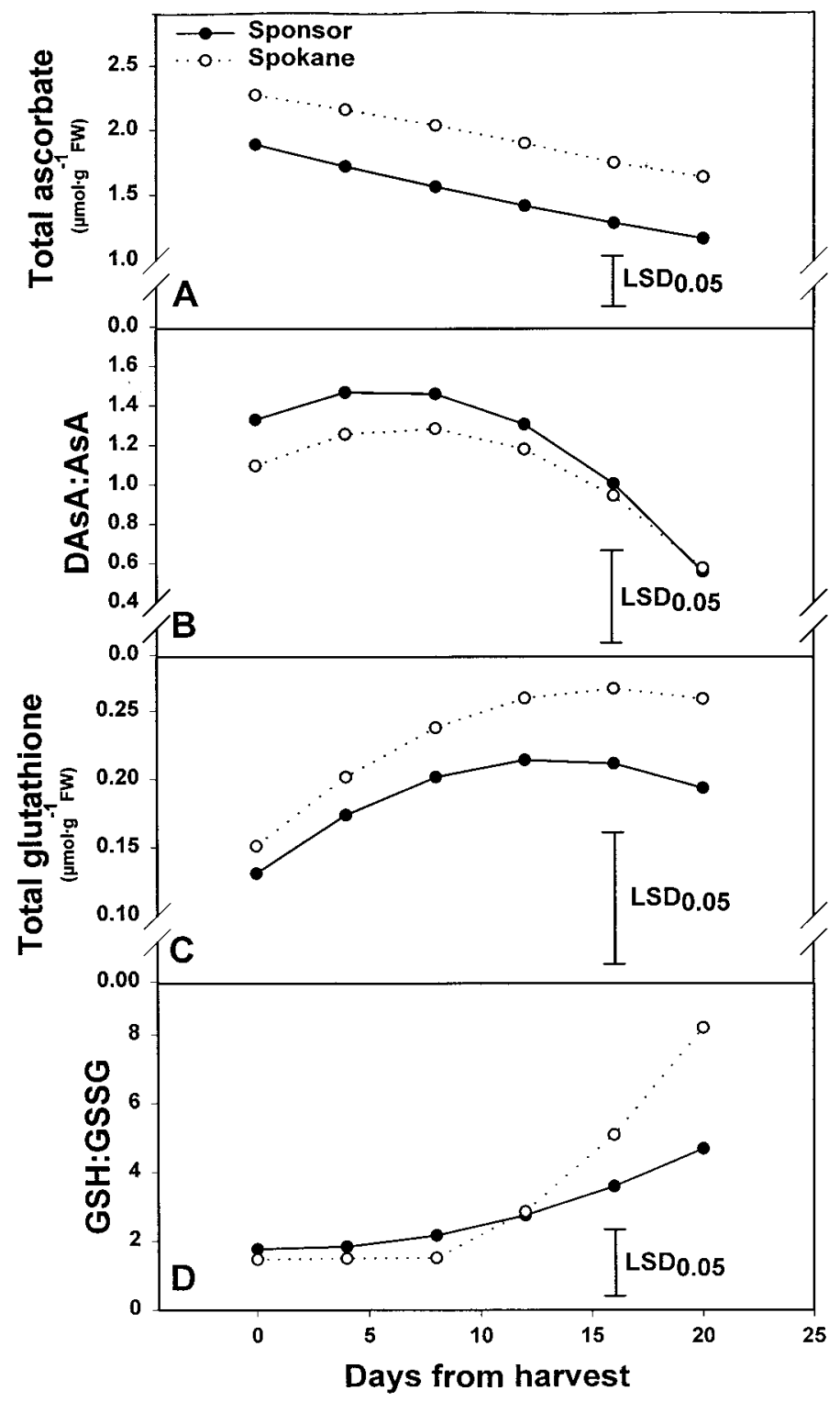

Fig.5. Changes in (A) total ascorbate, (B) DAsA:AsA, (C) total glutathione, and (D) GSH:GSSG values over time in detached leaves of Sponsor and Spokane spinach stored at $10^{\circ} \mathrm{C}$ in the dark with $\mathrm{RH} \geq 95 \%$. Plants were grown initially in a growth chamber. Symbols represent the means of six independent replicate samples from two harvests. 
Spokane, while having a higher rate of lipid peroxidation accumulation during postharvest storage, also exhibited a significant decline in ASPX activity, which converts $\mathrm{H}_{2} \mathrm{O}_{2}$ to $\mathrm{H}_{2} \mathrm{O}$ with concomitant oxidation of ascorbate. Less production of DAsA through decreased ASPX activity may have accounted for the relative stability of the DAsA:AsA values observed in detached leaves of Spokane. As SOD acts primarily to dismutate $\mathrm{O}_{2}^{-}$to $\mathrm{H}_{2} \mathrm{O}_{2}$, the gradual increase in SOD activity observed in Spokane leaves after detachment, while enhancing $\mathrm{O}_{2}^{-}$scavenging, may have acted in concert with decreasing ASPX and total ascorbate in augmenting cellular $\mathrm{H}_{2} \mathrm{O}_{2}$ levels. This agrees with similar results in detached and stored leaves of another spinach cultivar (Hodges and Forney, 2000), which suggested that declines in ASPX and ascorbate signified that regulation of $\mathrm{H}_{2} \mathrm{O}_{2}$ played an important role in both the dynamics and severity of senescence. Hydrogen peroxide, although not in itself very toxic, can be detrimental to plant metabolism through such actions as its reaction with $\mathrm{O}_{2}^{-}$in the metal-catalyzed Haber-Weiss reaction to form the very potent oxidizer $\bullet \mathrm{OH}$ (Salin, 1988). Detoxification of $\mathrm{H}_{2} \mathrm{O}_{2}$ is extremely important in regulating levels of AOS within plant systems.

Leaves of Sponsor, the cultivar exhibiting less lipid peroxidation than Spokane during postharvest storage, demonstrated a slightly more rapid loss in total ascorbate. The DAsA:AsA values also declined in this cultivar over storage, unlike in Spokane. Moreover, total glutathione did not increase in Sponsor leaves after detachment as observed in Spokane, and the GSH:GSSG ratios did not rise to the degree displayed by Spokane. Although ASPX activity did not decrease in this cultivar as it did in Spokane, it is not certain whether maintenance of this enzyme's activities prevented MDA accumulation that was observed in Spokane. Compared with Sponsor, it is quite possible that AOS production in Spokane was inherently greater, leading to a demonstrable increased rate of senescence. It is also possible that decreased ASPX activities shortly after detachment predisposed Spokane for later increased cellular AOS generation. DAsA:AsA and GSH:GSSG results do not suggest that capacities of other antioxidant enzymes such as dehydroascorbate reductase or glutathione reductase were affected in Spokane, but the possibility remains that other antioxidant compounds such as the carotenoids and/or tocopherols may have played a role in the more rapid onset of senescence in this cultivar as compared with Sponsor.

Oxidative stress can induce or enhance plant antioxidant levels. Although this has been shown primarily for plants exposed to suboptimal conditions (Foyer et al., 1994; Hodges, 2001; Hodges et al., 1997a), few studies provide evidence for enhancement of antioxidants during leaf senescence (Kingston-Smith et al., 1997). Our study has demonstrated that detached spinach leaves have the ability to elevate SOD activities, as well as levels of glutathione. Moreover, although CAT activities did not increase significantly over storage, this trend was certainly apparent. Foyer et al. (1997) suggest $\mathrm{H}_{2} \mathrm{O}_{2}$ plays a crucial role in mediating stress responses through signal transduction, leading to appropriate responses in cellular defence systems. The decline of ASPX in Spokane leaves may have enhanced $\mathrm{H}_{2} \mathrm{O}_{2}$ levels, stimulating both SOD activities and glutathione levels $8 \mathrm{~d}$ after detachment.

The present study has shown that two cultivars of spinach differing in their postharvest senescence rates exhibit differences in their antioxidant dynamics. Results support earlier work with spinach (Hodges and Forney, 2000) which implied that $\mathrm{H}_{2} \mathrm{O}_{2}$ regulation may play a critical role in the onset and dynamics of senescence. The process of detachment itself may have induced leaf senescence through such processes as reduced mineral nutrient availability and water loss, and future research designed to separate the direct effects of detachment from antioxidant flux in senescing leaves will be undertaken as well as efforts to elucidate $\mathrm{H}_{2} \mathrm{O}_{2}^{-}$generation mechanisms associated with senescence.

\section{Literature Cited}

Aebi, H.E. 1983. Catalase, p. 273-286. In: H.U. Bergmeyer (ed.). Methods of enzymatic analysis. vol 3. Verlag Chemie, Weinheim, Germany.

Bartoli, C.G., M. Simontacchi, and S. Puntarulo. 1996. Oxidative stress, antioxidant capacity and ethylene production during ageing of cut carnation (Dianthus caryophyllus) petals. J. Exp. Bot. 297:595-601.

Bradford, M.M. 1976. A rapid and sensitive method for the quantification of microgram quantities of protein using the principle of protein dye-binding. Anal. Biochem. 72:248-254.

Buchanan-Wollaston, V. 1997. The molecular biology of leaf senescence. J. Expt. Bot. 48:181-199.

Chamulitrat, W., M.F. Hughes, T.E. Eling, and R.P. Mason. 1991. Superoxide and peroxyl radical generation from the reduction of polyunsaturated fatty acid hydroperoxides by soybean lipoxygenase. Arch. Biochem. Biophys. 290:153-159.

Droillard, M.J., A. Paulin, and J.C. Massot. 1987. Free radical production, catalase, and superoxide dismutase activities and membrane integrity during senescence of petals of cut carnation (Dianthus caryophyllus). Physiol. Plant. 71:197-202.

Foyer, C.H., P. Descourvières, and K.J. Kunert. 1994. Protection against oxygen radicals: An important defence mechanism studied in transgenic plants. Plant. Cell. Environ. 17:507-523.

Foyer, C.H., H. Lopez-Delgado, J.F. Dat, and I.M. Scott. 1997. Hydrogen peroxide- and glutathione-associated mechanisms of acclimatory stress tolerance and signaling. Physiol. Plant. 100:241-254.

Genstat 5 Committee. 1997. Genstat release 4.1 reference manual. Clarendon Press, Oxford, United Kingdom.

Gossett, D.R., E.P. Millhollon, and M.C. Lucas. 1994. Antioxidant response to $\mathrm{NaCl}$ stress in salt-tolerant and salt-sensitive cultivars of cotton. Crop Sci. 34:706-714.

Griffith, O. 1980. Determination of glutathione and glutathione disulfide using glutathione reductase and 2-vinylpyridine. Anal. Biochem. 106:207-212.

Hakam, N. and J.P. Simon. 1996. Effect of low temperature on the activity of oxygen scavenging enzymes in two populations of the $\mathrm{C}_{4}$ grass Echinocloa crus-galli. Physiol. Plant. 97:209-216.

Hildebrand, D.F. 1989. Lipoxygenases. Physiol. Plant. 76:249-253.

Hodges, D.M. 2001. Chilling effects on active oxygen species and their scavenging systems in plants, p. 53-76. In: A. Basra (ed.). Crop responses and adaptations to temperature stress. Haworth Press, New York.

Hodges, D.M., C.J. Andrews, D.A. Johnson, and R.I. Hamilton. 1996. Antioxidant compound responses to chilling stress in differentially sensitive inbred maize lines. Physiol. Plant. 98:685-692.

Hodges, D.M., C.J. Andrews, D.A. Johnson, and R.I. Hamilton. 1997a. Antioxidant enzyme responses to chilling stress in differentially sensitive inbred maize lines. J. Expt. Bot. 48:1005-1113.

Hodges, D.M., C.J. Andrews, D.A. Johnson, and R.I. Hamilton. 1997b. Antioxidant enzyme and compound responses to chilling stress and their combining abilities in differentially sensitive maize hybrids. Crop Sci. 37:857-863.

Hodges, D.M., J.M. DeLong, C.F. Forney, and R.K. Prange. 1999. Improving the thiobarbituric acid-reactive-substances assay for estimating lipid peroxidation in plant tissues containing anthocyanin and other interfering compounds. Planta 207:604-611.

Hodges, D.M. and C.F. Forney. 2000. The effects of ethylene, depressed oxygen and elevated carbon dioxide on antioxidant profiles of senescing spinach leaves. J. Expt. Bot. 51:645-655.

Kanofsky, J.R. and B. Axelrod. 1986. Singlet oxygen production by soybean lipoxygenase isozymes. J. Biol. Chem. 261:1099-1104.

Kingston-Smith, A.H., H. Thomas, and C.H. Foyer. 1997. Chlorophyll $a$ fluorescence, enzyme and antioxidant analyses provide evidence for 
the operation of alternative electron sinks during leaf senescence in a stay-green mutant of Festuca pratensis. Plant Cell. Environ. 20:13231337.

Kunert, K.J. and M. Ederer. 1985. Leaf ageing and lipid peroxidation: The role of the antioxidants vitamin C and E. Physiol. Plant. 65:85-88.

Kuo, S.J. and K.L. Parkin. 1989. Chilling injury in cucumbers (Cucumis sativa $\mathrm{L}$.) associated with lipid peroxidation as measured by ethane evolution. J. Food Sci. 54:1488-1491.

Law, M.Y., S.A. Charles, and B. Halliwell. 1983. Glutathione and ascorbic acid in spinach (Spinacia oleracea) chloroplasts: The effect of hydrogen peroxide and of paraquat. Biochem. J. 210:899-903.

Li, L., J. Van Staden, and A.K. Jäger. 1998. Effects of plant growth regulators on the antioxidant system in seedlings of two maize cultivars subjected to water stress. Plant Growth. Reg. 25:81-87.

Lyons J.M., D. Graham, and P.L. Steponkus. 1979. The plant membrane in response to low temperature, p. 1-24. In: J.M. Lyons, D. Graham, and J.K. Raison (eds.). Low temperature stress in crop plants: The role of the membrane. Academic Press, New York.

McCord, J.M. and I. Fridovich. 1969. Superoxide dismutase: An enzymic function for erythrocuperin (hemocuprin). J. Biol. Chem. 224:60496055.

Meir, S., K. Kanner, B. Akiri, and S. Philosoph-Hadas. 1995. Determination and involvement of aqueous reducing compounds in oxidative defense systems of various senescing leaves. J. Agr. Food Chem. 43:1813-1819.

Nakano, A. and K. Asada. 1987. Purification of ascorbate peroxidase in spinach chloroplasts: Its inactivation in ascorbate-depleted medium and reactivation by monodehydroascorbate radical. Plant Cell. Physiol. 28:131-140.

Olmos, E., J.A. Hernández, F. Sevilla, and A. Hellín. 1994. Induction of several antioxidant enzymes in the selection of a salt-tolerant line of Pisum sativum. J. Plant Physiol. 144:595-598.

Philosoph-Hadas, S., S. Meir, and N. Aharoni. 1991. Effect of wounding on ethylene biosynthesis and senescence of detached spinach leaves. Physiol. Plant. 83:241-246.

Philosoph-Hadas, S., S. Meir, B. Akiri, and J. Kanner. 1994. Oxidative defense systems in leaves of three edible herb species in relation to their senescence rate. J. Agr. Food Chem. 42:2376-2381.

Ranieri, A., G. D’Urso, C. Nali, G. Lorenzini, and G.F. Soldatini. 1996. Ozone stimulates apoplastic antioxidant systems in pumpkin leaves. Physiol. Plant. 97:381-387.

Rao, M.V., G. Paliyath, and D.P. Ormrod. 1996. Ultraviolet-B- and ozone-induced biochemical changes in antioxidant enzymes of Arabidopsis thaliana. Plant Physiol. 110:125-136.

Salin, M.L. 1988. Toxic oxygen species and protective systems of the chloroplast. Physiol. Plant. 72:681-689.

Schöner, S. and G.H. Krause. 1990. Protective systems against active oxygen species in spinach: Response to cold acclimation in excess light. Planta 190:383-389.

Thompson, J.E. 1984. Physical changes in the membranes of senescing and environmentally stressed plant tissues, p. 85-108. In: M. Shinitzky (ed.). Physiology of membrane fluidity. CRC Press, Boca Raton, Fla. Thompson, J.E., J.H. Brown, G. Paliyath, J.F. Todd , and K. Yao. 1991. Membrane phospholipid catabolism primes the production of activated oxygen in senescing tissues, p. 57-66. In: E. Pell and K. Steffen (eds.). Active oxygen/oxidative stress and plant metabolism. Amer. Soc. Plant Physiol., Rockville, Md.

Trippi, V. and K.V. Thimann. 1983 The exudation of solutes during senescence of oat leaves. Physiol. Plant. 58:21-28

Wintermans, J.F.G.M. and A. De Mots. 1965. Spectrophotometric characteristics of chlorophylls $a$ nd $b$ and their pheophytins in ethanol. Biochem. Biophys. Acta 109:448-453.

Wismer, W.V., W.M. Worthing, R.Y. Yada, and A.G. Marangoni. 1998. Membrane lipid dynamics and lipid peroxidation in the early stages of low-temperature sweetening in tubers of Solanum tuberosum. Physiol. Plant. 102:396-410. 